Fábio Luiz Ferreira Scannavino ${ }^{2}$

Lourdes dos Santos-Pinto ${ }^{3}$

Antonio Carlos Hernandes ${ }^{4}$

\section{Sucção de alta potência no controle das partículas emitidas pelo sistema de abrasão a ar em consultório odontológico ${ }^{1}$ Control of particles emitted by air-abra-
sion system with high-power suction in a
dental office}

\begin{abstract}
Resumo
O objetivo do estudo foi avaliar a deposição de óxido de alumínio no campo operatório do cirurgião-dentista durante a utilização do sistema de abrasão a ar em consultório odontológico, bem como a efetividade da sucção de alta potência na captação desse pó. Por meio de um dispositivo para a coleta das partículas nos locais correspondentes às posições e distâncias de trabalho do profissional, dentes artificiais foram abrasionados. O sistema de sucção empregado para aspiração das partículas foi o de alta potência com sugador de saliva convencional e sugador com abertura ampliada por funil. A mensuração das partículas foi determinada pela quantidade em massa de óxido de alumínio depositada em placas de Petri. Os resultados obtidos por meio de estatística descritiva gráfica revelaram que a maior quantidade de pó se encontrava a $20 \mathrm{~cm}$ do operador e na posição de trabalho 9h, quando foi utilizado o sugador de saliva convencional. Uma vez comprovado que a sucção não é totalmente eficiente na aspiração do pó de óxido de alumínio, reforça-se a importância da proteção individual apropriada para o emprego seguro do sistema de abrasão a ar para pacientes e, principalmente, para os profissionais que trabalham com este tipo de tecnologia.
\end{abstract}

Palavras-chaves: abrasão dental por ar, suç̧ão, contaminação do ar, óxido de alumínio, consultório odontológico.

\begin{abstract}
This study aimed at evaluating not only the amount of aluminum oxide particles deposited in a dental office while a dentist is using a pressurized air abrasion system, but also how effectively high-power suction is able to remove the dust resulting from that process. Artificial teeth were abraded through a device, which collected the particles laid down on the operation site, exactly at the same distance kept by the dentist from the patient's mouth. A high-powered suction system was employed to absorb the particles with both, a conventional and a funnel-shaped saliva ejector. The amount of particles was determined by the aluminum oxide mass deposited in Petri plates. Results obtained and showed by means of statistic graphics, revealed that the greatest amount of abrasive particles was deposited at a distance of $20 \mathrm{~cm}$ from the center of the phantom head, at the $9 o^{\prime}$ clock operating position, using a conventional saliva ejector. Once the experiment confirmed that suction does not totally remove the aluminum oxide particles from the premises, it is extremely important that dentists and their patients are protected by the correct PPE during an air-abrasion process.
\end{abstract}

Keywords: dental air abrasion, suction, air contamination, aluminum oxide, dental office. 


\section{Introdução}

O aparelho de abrasão a ar foi introduzido na Odontologia por Black, em 1945. Ao ser capaz de remover estrutura dentária utilizando um jato de partículas abrasivas impulsionadas por ar comprimido sem produzir vibração, ruído e pressão, proporcionava grande conforto para os pacientes. No entanto, deixou de ser empregado após o desenvolvimento da turbina de alta rotação, que cortava a estrutura dentária mais rapidamente, produzindo cavidades com formas definidas, adequadas aos materiais restauradores da época.

Nos anos 1990, os aparelhos de abrasão a ar ressurgiram e, atualmente, apresentam uma tecnologia avançada com capacidade de controlar o fluxo das partículas abrasivas, ajustando a emissão das mesmas para a obtenção de preparos cavitários que conservem ao máximo a estrutura dentária sadia. Dessa maneira, o aparelho de abrasão a ar tem contribuído para o avanço tecnológico no preparo de cavidades juntamente com a evolução dos materiais adesivos, tornando-se uma ferramenta importante na Odontologia conservadora (WHITE \& EAKLE, 2000; PERUCHI, 2002).

Com a utilização crescente dessa nova tecnologia nos consultórios odontológicos,

\section{Material e Método}

A avaliação da deposição das partículas de óxido de alumínio emitidas por um sistema de abrasão a ar no campo de trabalho do cirurgião-dentista foi realizada em um consultório odontológico com $25 \mathrm{~m}^{2}$ e com todas as suas vias de acesso, como portas e janelas, fechadas. O condicionador de ar funcionava com as aletas retas, não-flertidas, de modo que o ar não ficasse direcionado para o campo operatório. Para a simulação da posição do paciente, bem como das posições de trabalho do profissional, a cadeira odontológica foi posicionada com inclinação de $45^{\circ}$ e distante $40 \mathrm{~cm}$ do solo.

Um dispositivo metálico foi acoplado à posição do cabeçote da cadeira odontológica e serviu como plataforma de suporte para a cabeça de um manequim. Dois braços articuláveis que sustentavam a peça de mão do aparelho de abrasão a ar e o sugador foram adaptados à plataforma de suporte. observamos que o pó produzido pelo aparelho de abrasão a ar, bem como os aerossóis de alta rotação e pontas sônicas, tem preocupado os profissionais quanto à possibilidade de contaminação do campo operatório e aos riscos à saúde de profissionais e pacientes (MALMSTROM et al., 2003).

Quando inaladas, as partículas de óxido de alumínio aparecem livremente nos brônquios e alvéolos peribronquiais, causando fibrose pulmonar. Além disso, estudo com animais de laboratório evidenciou que danos reversíveis podem ocorrer nas vias aéreas inferiores e irreversíveis, nas vias áreas superiores (KERR et al., 1957; PERUCHI, 2003).

A ausência de estudos sobre a contaminação do consultório odontológico quando se utiliza o aparelho de abrasão a ar e a falta de comprovação da eficiência dos mecanismos de aspiração do pó gerado nos procedimentos clínicos têm motivado estudos sobre o assunto (GOLDSTEIN \& PARKINS, 1994). Assim, o objetivo deste trabalho foi avaliar a deposição das partículas de óxido de alumínio nas posições de trabalho do cirurgiãodentista quando da utilização da sucção de alta potência para a captação do pó.

De um total de seis hastes, cinco foram posicionadas horizontalmente no espaço correspondendo às posições ergonômicas de trabalho do cirurgião-dentista destro sentado (SCHON, 1973; BENTLEY et al., 1994), acompanhando a distância pré-determinada de $40 \mathrm{~cm}$ do solo. Para Schon (1973), tomando-se como parâmetro os quadrantes de um relógio, o cirurgião-dentista pode alternar sua posição de trabalho de $7 \mathrm{~h}$ até $12 \mathrm{~h}$. Da mesma forma, Porto (1994) indicou as posições $3 \mathrm{~h}$ e $5 \mathrm{~h}$ para a auxiliar do cirurgião-dentista destro. Uma única haste foi acrescentada ao dispositivo no plano vertical, simulando a região nasal do operador.

Assim, o campo operatório foi definido pelas seis hastes metálicas, sendo que cada uma possuía $75 \mathrm{~cm}$ de comprimento total, graduadas a cada $5 \mathrm{~cm}$. Essas hastes estavam distribuídas em um raio de $180^{\circ}$ (posição horizontal), sendo a distância entre 
elas de $36^{\circ}$. Sobre as hastes foram adaptados suportes plásticos com $5 \mathrm{~cm}$ de diâmetro, posicionados a $20 \mathrm{~cm}, 40 \mathrm{~cm}$ e $60 \mathrm{~cm}$ do centro da cavidade bucal do manequim
(Figura 1), que suportavam placas de Petri (Bioplass ${ }^{\circledR}$ - PlastLabor, Rio de Janeiro-RJ, Brasil) para a coleta das partículas de óxido de alumínio (Figura 2).

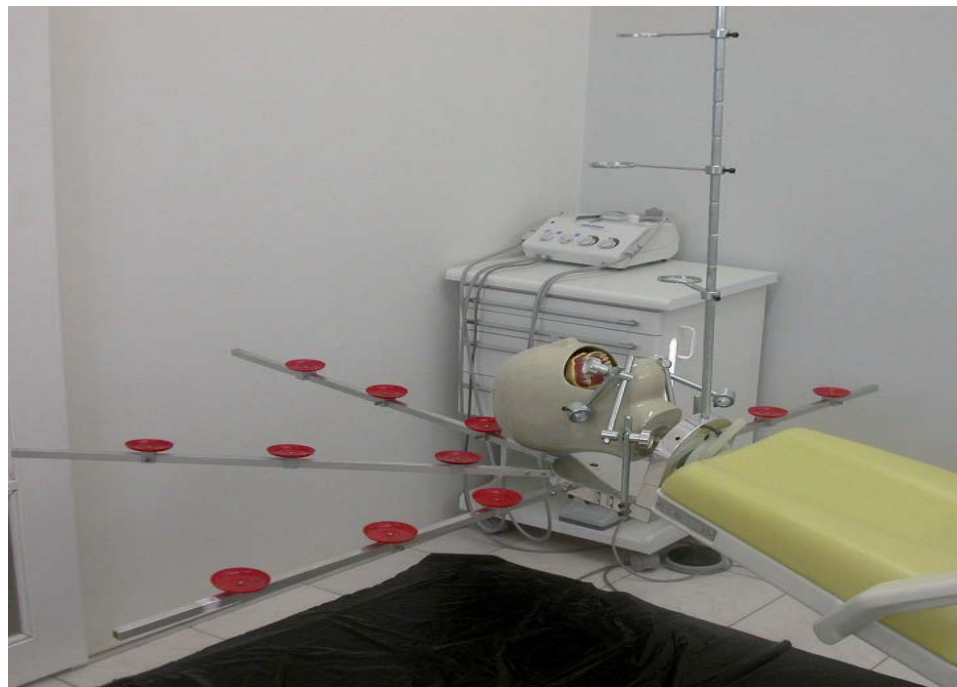

Figura 1 Estrutura do dispositivo metálico acoplado à cadeira odontológica com as hastes e os suportes plásticos delimitando as distâncias de $20 \mathrm{~cm}, 40 \mathrm{~cm}$ e $60 \mathrm{~cm}$ do centro da cavidade bucal

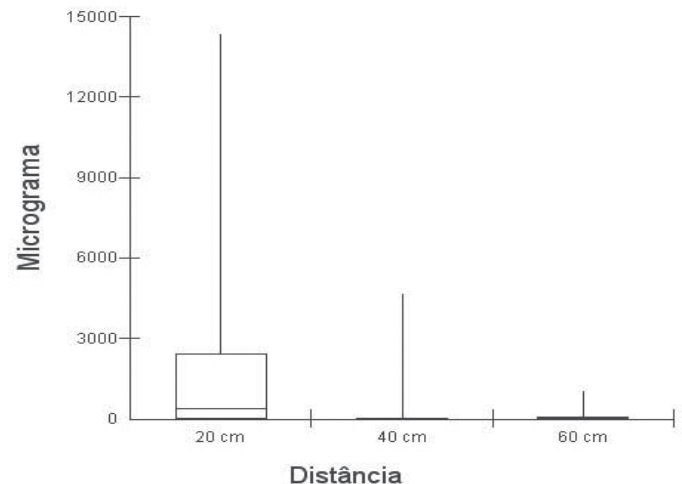

Figura 2 Deposição média das partículas de óxido de alumínio empregando o sugador com cânula modificada por funil nas 18 amostras para cada distância de $20 \mathrm{~cm}, 40 \mathrm{~cm}$ e $60 \mathrm{~cm}$

O aparelho de abrasão a ar empregado foi o PrepStar ${ }^{\mathrm{TM}}$ (Danville Engeneering, USA) ajustado com pressão de 80 psi, ponta ativa com $80^{\circ}$ de angulação e $0,48 \mathrm{~mm}$ de diâmetro interno. E, para a captação das partículas de óxido de alumínio, utilizouse um sistema de sucção de alta potência Ciclone ${ }^{\circledR}$ (1 HP, 1540 W, 50/60Hz - Dabi Atlante, Ribeirão Preto-SP, Brasil) com sugador de saliva convencional (DFL $\AA$ - Rio de Janeiro-RJ, Brasil), comumente utilizado no consultório odontológico, e um sugador com um funil com 55 mm de diâmetro adaptado à ponta da cânula. Para garantir o total vedamento entre a porção da cânula do sugador e o funil, foi utilizada uma fita isolante.
Com o objetivo de somente avaliar partículas de óxido de alumínio, realizou-se neste estudo a análise térmica, que consiste em um superaquecimento dos materiais componentes da abrasão e um posterior gráfico computadorizado (MEDEIROS, 2001). A partir da análise térmica, comprovou-se que a quantidade de material dentário presente no pó coletado após a realização de um preparo cavitário com abrasão a ar foi insignificante. Sendo assim, passou-se a avaliar tão somente a quantidade do pó de óxido de alumínio depositado durante um procedimento com abrasão a ar.

Para a realização dos preparos cavitários, um dente posterior, confeccionado em resina auto-polimerizável (Duralay Relian- 
ce Dental Co., Chicago, USA), foi isolado com lençol de borracha (Madeitex® - São José dos Campos-SP, Brasil) e grampo $\mathrm{n}^{\circ}$ 26 (Ivory $^{\circledR}$ - Heraeus-Kulzer - Hanau, Germany). A ponta ativa do aparelho de abrasão a ar foi posicionada com o auxílio de uma lâmina de cera a $2 \mathrm{~mm}$ da superfície oclusal do dente e o jato de óxido de alumínio aplicado por 15 segundos. Do lado oposto foram posicionados os sugadores.

A quantidade de partículas de óxido de alumínio depositada foi calculada com base na diferença em massa do recipiente (placa de Petri). Assim, antes da realização dos preparos com o sistema de abrasão a ar, as placas de Petri foram vaselinadas e pesadas cinco vezes em balança de alta precisão (Mettler AE 163 - Quality Lab Excess,

\section{Resultado}

A quantificação das partículas de óxido de alumínio presentes nas placas de Petri, distribuídas em função da posição de trabalho e da distância do operador em relação ao centro da boca do manequim, está descrita nas Tabelas 1 e 2 . Os
USA), em laboratório com total isolamento de corrente de ar ou umidade, sendo obtida a massa inicial. As hastes metálicas abrigavam um total de dezoito suportes plásticos que, por sua vez, sustentavam dezoito placas de Petri para cada preparo, sendo repetido cinco vezes, resultando um total de 180 placas avaliadas.

Após a realização do abrasionamento do dente artificial com o sistema de abrasão a ar, as placas de Petri foram pesadas novamente e a massa das partículas de óxido de alumínio depositada foi determinada pela diferença entre as massas final e inicial. A quantidade de partículas de óxido de alumínio obtida foi tabulada e, posteriormente, realizou-se a análise estatística por meio de gráficos.

resultados evidenciaram que a quantidade total de partículas depositadas no campo operatório foi maior quando se utilizou sugador de saliva convencional para a captação do pó.

Tabela 1 Quantidade total e média das partículas de óxido de alumínio das 18 amostras em cada distância de 20 cm, $40 \mathrm{~cm}$ e $60 \mathrm{~cm}$ do centro da cavidade bucal do manequim

\begin{tabular}{|c|c|c|c|c|c|}
\hline \multicolumn{2}{|c|}{ Sugador / Distância } & \multirow{2}{*}{$\begin{array}{l}20 \mathrm{~cm} \\
21,50\end{array}$} & \multirow{2}{*}{$\begin{array}{l}40 \mathrm{~cm} \\
5,07\end{array}$} & \multirow{2}{*}{$\begin{array}{l}60 \mathrm{~cm} \\
1,90\end{array}$} & \multirow{2}{*}{$\begin{array}{c}\text { Total absoluto }(\mu \mathrm{g}) \\
28,49\end{array}$} \\
\hline & Total $\left(10^{3} \mu \mathrm{g}\right)$ & & & & \\
\hline \multirow[t]{3}{*}{ De saliva convencional } & Média $\left(10^{3} \mu \mathrm{g}\right)$ & 3,58 & 0,84 & 0,31 & \\
\hline & desvio padrão & 2,97 & 0,33 & 0,10 & \\
\hline & Total $\left(10^{3} \mu \mathrm{g}\right)$ & 18,10 & 4,80 & 1,20 & 24,10 \\
\hline \multirow[t]{3}{*}{ Modificado por funil } & Média $\left(10^{3} \mu \mathrm{g}\right)$ & 3,01 & 0,80 & 0,20 & \\
\hline & desvio padrão & 1,27 & 0,010 & 0,002 & \\
\hline & \multicolumn{2}{|c|}{ Diferença Relativa (\%) } & & & 18 \\
\hline
\end{tabular}

A distribuição das partículas de óxido de alumínio acumuladas em função da distância do operador evidenciou que a deposição no campo operatório foi sempre maior próximo à boca do paciente $(20 \mathrm{~cm})$, independentemente do tipo de sugador utilizado. Nas distâncias de $40 \mathrm{~cm}$ e $60 \mathrm{~cm}$ ocorreu expressiva redução na quantidade de partículas depositadas nas placas (Figuras 2 e 3 ). 
Tabela 2 Quantidade total e média das partículas de óxido de alumínio das 18 amostras para cada posição de trabalho do operador em função das hastes

\begin{tabular}{|c|c|c|c|c|c|c|c|c|}
\hline \multicolumn{2}{|c|}{ Sugador / Haste } & \multirow{2}{*}{$\begin{array}{c}n^{\circ} 1 \\
10,89\end{array}$} & \multirow{2}{*}{$\begin{array}{l}n^{\circ} 2 \\
3,03\end{array}$} & \multirow{2}{*}{$\begin{array}{l}n^{\circ} 3 \\
1,90\end{array}$} & \multirow{2}{*}{$\begin{array}{l}n^{\circ} 4 \\
1,85\end{array}$} & \multirow{2}{*}{$\begin{array}{l}n^{\circ} 5 \\
1,46\end{array}$} & \multirow{2}{*}{$\begin{array}{l}n^{\circ} 6 \\
9,34\end{array}$} & \multirow{2}{*}{$\begin{array}{c}\text { Total absoluto } \\
28,49\end{array}$} \\
\hline & Total $\left(10^{3} \mu \mathrm{g}\right)$ & & & & & & & \\
\hline De saliva convencional & Média $\left(10^{3} \mu \mathrm{g}\right)$ & 3,62 & 1,00 & 0,63 & 0,619 & 0,48 & 3,11 & \\
\hline & desvio padrão & 3,80 & 1,30 & 0,61 & 0,48 & 0,20 & 4,17 & \\
\hline & Total $\left(10^{3} \mu \mathrm{g}\right)$ & 20,02 & 0,81 & 0,07 & 0,11 & 0,02 & 0,30 & 24,11 \\
\hline Modificado por funil & Média $\left(10^{3} \mu \mathrm{g}\right)$ & 6,67 & 0,27 & 0,02 & 0,03 & 0,009 & 1,02 & \\
\hline & desvio padrão & 6,86 & 0,42 & 0,01 & 0,01 & 0,008 & 1,67 & \\
\hline \multicolumn{8}{|c|}{ Diferença Relativa (\%) } & 18 \\
\hline
\end{tabular}

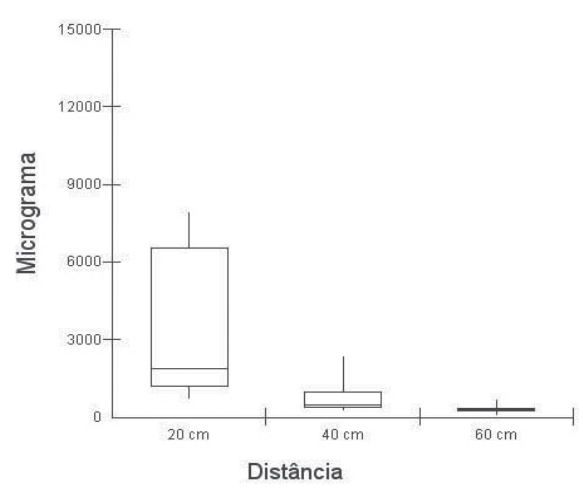

Figura 3 Deposição média de partículas de óxido de alumínio empregando sugador de saliva convencional nas 18 amostras para cada distância de $20 \mathrm{~cm}, 40 \mathrm{~cm}$ e $60 \mathrm{~cm}$.

Considerando a deposição das partículas em função da posição das hastes, observamos que maior quantidade de partículas de óxido de alumínio estava presente

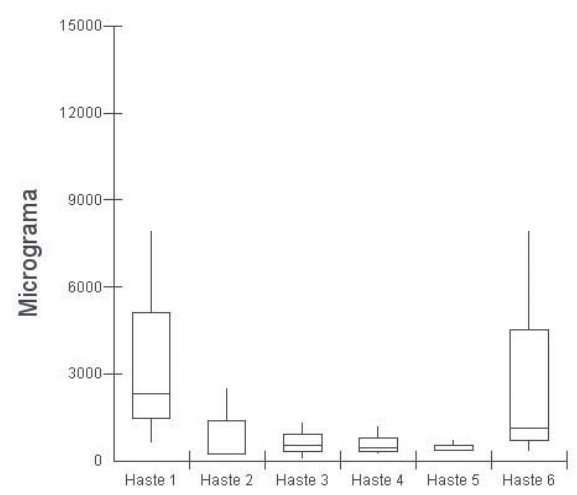

Figura 4 Quantidade média de partículas de óxido de alumínio captadas pelas hastes, contendo um total de 18 amostras, empregando o sugador de saliva convencional na haste 1, situada na posição de trabalho 9h, especialmente quando foi empregado o sugador com cânula modificada por funil (Figuras 4 e 5). 


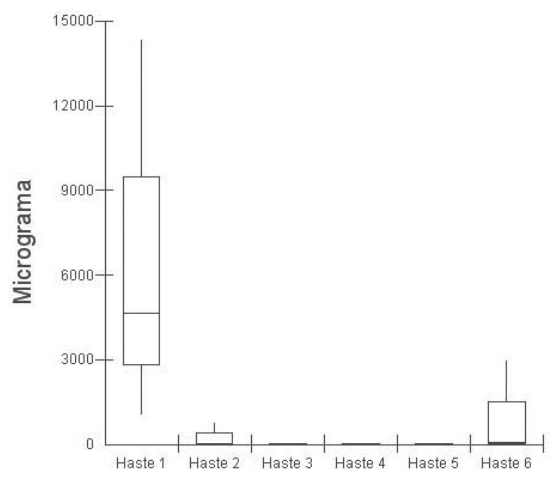

Figura 5 Quantidade média de partículas de óxido de alumínio captadas pelas hastes, contendo um total de 18 amostras, empregando sugador com cânula modificada por funil

\section{Discussão}

A grande pressurização imposta às partículas de óxido de alumínio no momento em que o aparelho de abrasão a ar é acionado faz com que as mesmas, ao incidirem sobre a estrutura dentária, retornem para o campo operatório de uma forma desorganizada e sem direcionamento.

A falta de domínio na operação do aparelho de abrasão a ar, bem como a ausência de uma sucção eficiente, resulta em uma excessiva quantidade de óxido de alumínio dispersa no campo operatório. Conseqüentemente, o risco da inalação dessas partículas, tanto pelo profissional como pela sua equipe e paciente, tem sido considerado (GOLDSTEIN \& PARKINS, 1994).

A inalação de partículas abrasivas por animais de laboratório colocados em uma atmosfera que continha esse tipo de pó havia sido reportada por Kerr et al. (1957), que observaram a presença dessas partículas livres nos brônquios e alvéolos peribronquiais. E, mesmo após o relançamento dos aparelhos de abrasão a ar com tecnologia mais sofisticada, Peruchi (2003) demonstrou que a inalação das partículas de óxido de alumínio liberadas por um aparelho de abrasão a ar causou danos reversíveis às vias aéreas inferiores e irreversíveis às vias aéreas superiores de camundongos.

No presente estudo, observamos que o maior acúmulo de partículas de óxido de alumínio ocorreu quando utilizamos o sugador de saliva convencional. A adaptação de um funil, ampliando a área de sucção (55 mm de diâmetro), promoveu uma redução de $18 \%$ na quantidade de partículas depositadas (Tabela 1).
Quando consideramos a distância do operador em relação ao centro da boca do manequim, a maior deposição de partículas de óxido de alumínio ocorreu a 20 $\mathrm{cm}$, com o sugador de saliva convencional (Figura 2). No entanto, ressaltamos que, na Figura 3, existiu uma variação grande em função das distâncias, possivelmente justificada pela formação de um anteparo (cânula modificada), em que partículas em alta velocidade refletiam no obstáculo e retornavam ao campo operatório na sua menor distância $(20 \mathrm{~cm})$.

Segundo Worral et al. (1987), as distâncias de trabalho localizadas mais próximas da cavidade bucal parecem ser as mais vulneráveis, pois, avaliando a contaminação bacteriana durante a utilização de jatos de bicarbonato de sódio, observou-se que a maior contagem das colônias de bactérias também ocorreu na posição mais próxima do cabeçote da cadeira odontológica.

Nas distâncias de $40 \mathrm{~cm}$ e $60 \mathrm{~cm}$ do centro da boca, a quantidade em massa de óxido de alumínio depositada no campo operatório foi semelhante para os dois tipos de sugadores (Figuras 2 e 3). A redução gradual verificada na deposição das partículas na distância de $20 \mathrm{~cm}$ até $60 \mathrm{~cm}$, possivelmente, pode ser explicada pela perda de energia das partículas de óxido de alumínio ao incidirem na superfície dentária ou em qualquer outro anteparo. Black (1950) já havia reportado que a energia com que a partícula de óxido de alumínio deixava a ponta ativa do aparelho determinava a distância por ela percorrida. Da mesma forma, Peruchi et al. (2002) observaram que uma das razões pela qual o tempo de aplicação do aparelho de abrasão a ar não influen- 
ciava no tamanho da cavidade preparada em dente decíduo era devido ao fato de que a distância máxima a ser percorrida pelas partículas dependia da energia com que elas deixavam o aparelho.

Em relação às posições de trabalho do operador, representadas pelas hastes, a maior deposição de partículas de óxido de alumínio ocorreu na haste 1 (posição 9h) com o sugador modificado por funil. Contudo, o emprego do sugador de saliva convencional também permitiu a deposição de quantidade significativa de partículas (Figuras 4 e 5). Esse resultado é preocupante quanto ao risco de inalação das partículas, pois, segundo Porto (1994), a posição 9h é consagrada pelos estudiosos em ergonomia e a mais adotada pelos cirurgiões-dentistas, uma vez que permite trabalhar em visão direta mesmo nas regiões de difícil acesso.

Quando comparamos o valor total de partículas de óxido de alumínio depositadas no campo operatório estudado, observamos que o sugador modificado por funil promoveu um menor acúmulo de pó, levando-nos a inferir que a ampliação em aproximadamente sete vezes na abertura da cânula sugadora resultou em um aumento na eficiência da captação de partículas. Esses resultados não corroboram com os apresentados por Liebenberg (1997), que, utilizando um dispositivo intra-oral na sucção de partículas de óxido de alumínio, observou que o aumento do diâmetro do dispositivo de sucção alterou

\section{Conclusão}

Os resultados obtidos neste estudo nos mostraram que a maior deposição das partículas de óxido de alumínio ocorreu a 20 cm do centro da cavidade bucal do manequim e na posição de trabalho $9 \mathrm{~h}$ do operador destro (haste 1), empregando o sugador de saliva convencional.

No entanto, a ampliação da abertura da cânula sugadora aumentou a eficiência na captação das partículas abrasivas, princi-

\section{Referências Bibliográficas}

BENTLEY, C. D. et al. Evaluating spatter and aerosol contamination during dental proce- a eficiência deste mecanismo, resultando na diminuição do poder de sucção.

Ao compararmos a quantidade de partículas depositada na haste 1 (posição 9h do operador destro) e na haste 5 (auxiliar para operador destro), observamos que os dois tipos de sugadores foram eficientes, resultando na diminuição da deposição das partículas na posição da auxiliar, especialmente para o sugador modificado.

Quando comparamos a quantidade de partículas depositadas nas hastes 1 (posição $9 \mathrm{~h}$ do operador destro) e 6 (posição da região da cavidade nasal do operador destro), notamos que os valores são muito próximos para o sugador de saliva convencional, diferentemente do que ocorreu para o sugador modificado, em que a haste 6 coletou menos partículas que a haste 1 . Esse fato nos sugere que as partículas de óxido de alumínio em alta velocidade podem ter batido no anteparo do sugador e alterado seu curso, depositando-se na posição do operador. A segunda possibilidade para essa maior deposição de partículas na haste 1 (posição 9h) é que a sucção em alta potência propiciou uma região de vácuo na ponta ativa do funil que repelia as partículas de óxido de alumínio, direcionandoas para o lado do operador. A redução das partículas de óxido de alumínio na haste 6 com o sugador modificado por funil foi um resultado relevante, principalmente pelo fato desta haste simular a região da cavidade nasal do operador.

palmente na região da cavidade nasal do operador.

Como a deposição de partículas de óxido de alumínio se concentra especialmente nas áreas mais próximas ao cabeçote da cadeira odontológica, torna-se importante, quando da utilização do sistema de abrasão a ar, o uso de equipamentos de proteção individual e um sistema de sucção eficiente para prevenir futuros danos à saúde dos profissionais.

dures. J. Am. Dent. Assoc., v. 125, n. 5, p. 579-584, 1994. 
BLACK, R. B. Airbrasive: some fundamentals. J. Am. Dent. Assoc., v. 41, n. 6, p. 701710, 1950.

GLENWRIGHT, H. D.; KNIBBS, P. J.; BURDON, D. W. Atmospheric contamination during use of an air polisher. British Dental Journal, v. 159, n. 9, p. 294-297, 1985.

GOLDSTEIN, R. E.; PARKINS, F. M. Airabrasive technology: its new role in restorative dentistry. J. Am. Dent. Assoc., v. 125, n. 5, p. 551-557, 1994.

KOFFORD, K. R.; WAKEFIELD, C. W.; MURCHISON, D. F. Aluminum oxide air abrasion particles: a bacteriology and SEM study. Quintessence Inter., v. 32, n. 3, p. 243-248, 2001.

KERR, D. A.; RAMFJORD, S.; GRAPERAMFJORD, G. Effect of inhalation of airabrasive powder. Journal Dental Research, v. 36, n. 5, p. 721-731, 1957.

LEGNANI, P. et al. Atmospheric contamination during dental procedures. Quintessence Inter., v. 25, n. 6, p. 435-439, 1994.

LIEBENBERG, W. H. A useful evacuation aid for intraoral air-abrasive devices. Quintessence Inter., v. 28, n. 2, p. 105-108, 1997.

MALMSTROM, H. S.; CHAVES, Y.; MOSS, M. E. Patient preference: conventional rotary handpieces or air abrasion for cavity preparation. Operative Dentistry, v. 28, n. 6, p. 667-671, 2003.

MEDEIROS, I. S. Dispositivos LED para polimerização de resinas compostas dentais: comparação com outras fontes de luz.
2001. 113 f. Dissertação (Mestrado em Física) - Instituto de Física, Universidade de São Paulo, São Carlos.

PERUCHI, C. et al. Evaluation of cutting patterns produced in primary teeth by an air-abrasion system. Quintessence Inter., v. 33, n. 4, p. 279-283, 2002.

PERUCHI, C. Avaliação da efetividade de corte de diferentes aparelhos de abrasão a ar e o efeito da inalação das partículas de óxido de alumínio. 2003. 103 f. Tese (Doutorado em Odontopediatria) - Faculdade de Odontologia, Universidade Estadual Paulista, Araraquara.

PORTO, F. A. O consultório odontológico. São Carlos: Scritti, 1994.

SANTOS-PINTO, L. et al. Evaluation of cutting patterns produced with air abrasion systems using different tip designs. Operative Dentistry, v. 26, n. 3, p. 308-312, 2001

SCHON, F. Trabajo en equipo en la práctica odontológica. Berlim: Quintessence Books, 1973.

WHITE, J. M.; EAKLE, S. Rationale and treatment approach in minimally invasive dentistry. J. Am. Dent. Assoc., v. 131, p. 1319, 2000.

WORRAL, S. F.; KNIBBS, P. J.; GLENWRIGHT, H. D. Methods of reducing bacterial contamination of the atmosphere arising from use of an air-polisher. British Dental Journal, v. 163, n. 4, p. 118-119, 1987. 